\title{
EFFECT OF DEEP CRYOGENIC TREATMENT ON SURFACE INTEGRITY AND DIMENSIONAL STABILITY OF D2 TOOL STEEL
}

\author{
Tushar M. Sonar ${ }^{1}$, Sachin V. Lomte ${ }^{2}$ \\ ${ }^{1}$ Research Student, Mechanical Engineering, Maharashtra Institute of Technology, Aurangabad, Maharashtra, India \\ ${ }^{2}$ Associate Professor, Mechanical Engineering, Maharashtra Institute of Technology, Aurangabad, Maharashtra, \\ India
}

\begin{abstract}
Deep cryogenic treatment is an add-on process to conventional heat treatment in which material is treated at cryogenic temperature. The mechanical properties of the tool steel are significantly improved by Deep Cryogenic treatment. Surface integrity and dimensional stability is having greater impact on the functional performance of the tool during service conditions. The objective of this work is to investigate the effect of deep cryogenic treatment on the surface inte grity and dimensional stability of the D2 tool steel. The metallographic samples and Navy C Rings of D2 Tool steel were treated at cryogenic temperature of $193^{\circ} \mathrm{C}$ after hardening and tempering. Results have shown improvement in surface roughness. The improved surface roughness is attributed to the release of tensile residual stresses and more precipitation and uniform distribution of fine secondary carbides. DCT have higher shape distortion than CHT. The distortions in DCT can be attributed to the section sensitivity of D2 Tool steel.
\end{abstract}

Keywords: Surface integrity, distortion, precipitation of secondary carbides, section sensitivity

\section{INTRODUCTION}

D2 Tool steel is high carbon high chromium tool steel used for cutting tools and dies. Surface integrity and dimensional stability are the important parameters that affects on the functional performance of the tool during service condition. Surface integrity is the sum of external surface topography i.e. surface roughness and the subsurface metallurgy i.e. the nature of subsurface layers with respect to the base. The surface properties affects on the functional performance of a tool such as fatigue strength, corrosion rate, fracture toughness and tribological behavior such as friction, wear and lubrication and accuracy of dimensions [1]. The dimensional changes in tool steel due to quenching need to be considered in the design, manufacturing and use of tooling. The distortions that are encountered during the process of hardening the tool steel are the changes in size and shape of the tool. Size distortion involves linear or volumetric changes in dimensions due to expansion or contraction and shape distortion includes changes in its geometrical form due to twisting, bending etc. Size distortion occurs due to the changes in microstructure during the heat treatment. Shape distortion is mainly due to the residual stresses developed due to the large temperature gradient during the quenching process [2]. Dimensional stability is significant requirement for the D2 Tool steel applications. Tool steel parts are section sensitive. For the same chemical composition there are changes in the mechanical properties of the tool steel with varying thickness of the section. The section sensitivity depends on the cooling rate. For thin sections the cooling rate is high whereas for thick sections it is low. This contributes to the thermal stresses during quenching and affects on the dimensional stability of the tool steel. Navy C Ring test is the standard test used for evaluating the quench distortion of the material [3]. Navy C Ring has both thin and thick section which allows the shape of the sample to change during quenching [4].

Deep cryogenic treatment has been proved as an effective technique to increase the hardness, fatigue strength, wear resistance, impact toughness and extended the tool life. Deep Cryogenic treatment is a process of treating the materials at very low temperature. American Cryogenic society defines deep cryogenic treatment as the process in which material is cooled from the room temperature to Cryogenic temperature generally $-196^{\circ} \mathrm{C}$. It is soaked at this temperature for 24 hours and heated slowly to room temperature. The entire cycle is completed in 36 to 48 hours depending on the size and weight of the material. In CT the tool steel is treated at $-196^{\circ} \mathrm{C}$. it is known that the $\mathrm{Mf}$ temperature of the tool steel family lies between $-80^{\circ} \mathrm{C}$ to $-120^{\circ} \mathrm{C}$ therefore during the $\mathrm{CT}$ the complete transformation of retained austenite to martensite takes place by default. Amini et. al. [5] investigated the effect of deep cryogenic treatment on the mechanical properties of 80CrMo12 5 tool steel and concluded that DCT samples have high dimensional stability than CHT sample due to the complete transformation of retained austenite into martensite. Bensley et. al. [6] also confirmed that the dimensional stability of SCT and DCT specimens were higher than CHT specimens. Leskovesk and Ule [7] researched out the influence of deep cryogenic treatment on the microstructure, mechanical properties and dimensional changes of Vacuum heat treated HSS and concluded that the deep cryogenic treatment after vacuum heat treatment extended the austenite to martensite transformation and thus resulted in improved dimensional stability of HSS Navy C Rings after any subsequent tempering however the distortion of gap width increased 
significantly due to the transformational stress along with the thermal stresses. Lomte [8] claimed that deep cryogenic treatment and tempering is necessary to reduce the extent of residual stresses having significant effect on the dimensional stability of tool steel. According to Diekman the cryogenic treatment of the workpiece before heat treatment results in less distortion in heat treatment and thus amount of grinding required is less to flatten or to resize the workpiece [9]. D. Silva el. al. [10] concluded that the cryogenic treatment results in maximum transformation of retained austenite into martensite thus achieving more dimensional stability.

Research has proved that Cryogenic treatment has resulted in the improved mechanical properties of tool steel. Besides the improved mechanical properties, the surface integrity and dimensional stability of the D2 Too steel is important as well. In the literature there is absence of systematic investigation on the effect of deep cryogenic treatment on the surface integrity and dimensional stability of D2 Tool steel. Thus this wok aims at investigating the effect of deep cryogenic treatment on the surface integrity and dimensional stability of D2 Tool steel. Navy C Ring test was performed to study the dimensional stability of D2 Tool steel.

\section{EXPERIMENTAL METHODOLOGY}

The material selected for the investigation is D2 Tool Steel containing $1.61 \% \mathrm{C}, 0.30 \% \mathrm{Mn}, 11.50 \% \mathrm{Cr}, 0.15 \% \mathrm{Ni}$, $0.43 \%$ Mo, $0.014 \%$ S, $0.018 \%$ P, $0.25 \%$ Si, $0.16 \%$ V, $0.077 \% \mathrm{~W}$ etc. The D2 Tool steel was received in normalized condition as bar in two forms; round and rectangle. The material with round section of Size $60 \mathrm{~mm}$ diameter was used for making Navy C-rings. The Navy Crings were manufactured by $\mathrm{VMC}$ as per the standard dimensions shown in fig.1. The D2 Tool steel samples of size $30 \mathrm{~mm}$ X $30 \mathrm{~mm}$ X $10 \mathrm{~mm}$ were cut from a rectangular bar of size $65 \mathrm{~mm} \mathrm{X} 32 \mathrm{~mm}$ for surface roughness test and hardness test.

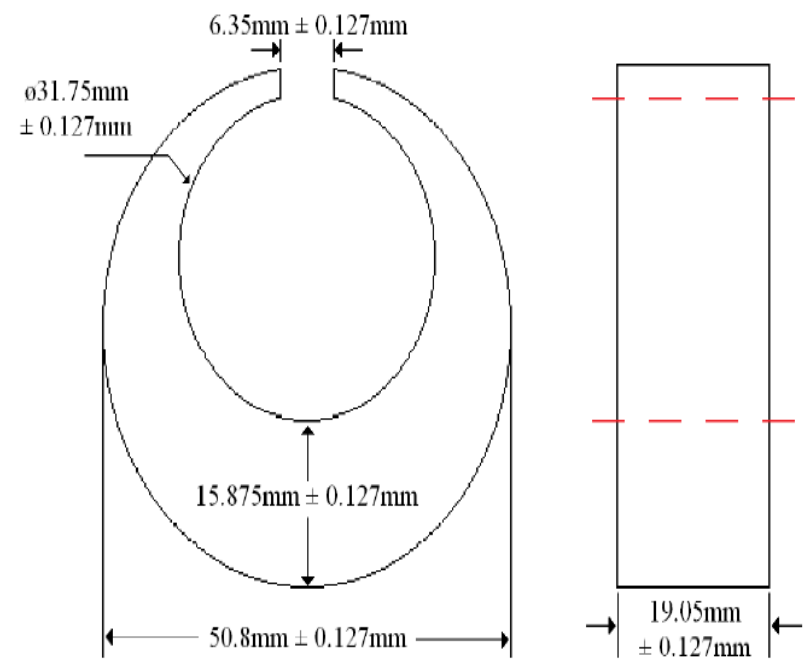

Fig -1: Standard dimensions of Navy C Ring [4]
The D2 Tool steel metallographic samples and Navy C-ring specimens were subjected to Conventional heat treatment (CHT) and deep cryogenic treatment (DCT). The vacuum heat treatment consists of hardening and tempering. The deep cryogenic treatment is an add-on process to conventional heat treatment performed after hardening and tempering. The D2 Metallographic samples and the Navy Cring specimens were heat treated in a horizontal vacuum furnace with a uniform high pressure gas quenching using $\mathrm{N}_{2}$ at a pressure of 5 bar. The samples were first preheated at $650^{\circ} \mathrm{C}$ for two hours followed by second preheating at $830^{\circ} \mathrm{C}$ for 1 hour 45 minutes, austenitized at a temperature of $1040^{\circ} \mathrm{C}$ for 1 hour and gas quenched to $100^{\circ} \mathrm{C}$. The samples were then tempered at a temperature of $540^{\circ} \mathrm{C}$ for 4 hours. The Vacuum heat treated D2 Tool Steel metallographic samples and Navy C-ring specimens were deep cryogenically treated at a lowest temperature of $193^{\circ} \mathrm{C}$. The samples were cooled down from room temperature to $-193^{\circ} \mathrm{C}$ at a cooling rate of $0.268^{\circ} \mathrm{C} / \mathrm{min}$, soaked at this temperature for 24 hours and then heated to the room temperature at the same rate that of cooling. The deep cryogenically treated samples were double tempered at $150^{\circ} \mathrm{C}$ for 2 hour. Table 1 shows the heat treatment and deep cryogenic treatment performed on D2 Tool steel.

Table -1: Different processes and sample coding of D2 Tool Steel

\begin{tabular}{|l|l|}
\hline $\begin{array}{l}\text { Sample } \\
\text { Code }\end{array}$ & Treatment \\
\hline CHT & Quenching $\left(1040^{\circ} \mathrm{C}\right)+$ Tempering $\left(540^{\circ} \mathrm{C}\right)$ \\
\hline DCT & $\begin{array}{l}\text { Quenching }\left(1040^{\circ} \mathrm{C}\right)+\text { Tempering }\left(540^{\circ} \mathrm{C}\right) \\
+ \text { Deep Cryogenic treatment }\left(-193^{\circ} \mathrm{C}\right)+ \\
\\
\text { Double Tempering }\left(150^{\circ} \mathrm{C}\right)\end{array}$ \\
\hline
\end{tabular}

\subsection{Surface Roughness Test}

The most commonly used roughness amplitude parameters to assess the coarseness of the surface produced by grinding, turning, and milling processes are Ra and Rt. The Surface Roughness Analysis was performed using a Taylor Hobson, Seltronic 3 profilometer. The cut-off length was selected at $0.8 \mathrm{~mm}$ and the roughness measurements were performed with an average of 3 measurements on each D2 Tool steel metallographic sample.

\subsection{Hardness Test}

The Rockwell hardness test was performed as per the ASTM standard E18-15. The Rockwell hardness scale C was selected for D2 Tool Steel with Diamond cone indenter and $150 \mathrm{Kg}-\mathrm{f}$ total load. Hardness was measured on metallographic samples of D2 Tool Steel with an average of 5 measurements on each metallographic sample.

\subsection{Navy C Ring Test / Dimensional Stability Test}

The dimensions of the Navy C-ring which changes during quenching were divided into size and shape distortions. Size distortion includes inner and outer diameters, thickness and gap width of the Navy C-ring sample and Shape distortion includes flatness, cylindricity and roundness [4]. CMM 
(Cordimesur 6.10.5) was used to measure the dimensions of the D2 Tool steel Navy C-ring samples. The dimensions were measured at top, middle and bottom. The average of 3 readings was taken as final reading of each dimensional parameter. The dimensions of the C-ring samples were measured before and after heat treatment and after cryogenic treatment.

\subsection{Microstructure Test}

The microstructural characterization was performed by Optical Microscopy technique. The metallographic samples were polished and etched with Picral etchant (4g Picric acid and $100 \mathrm{ml}$ Ethanol). The microstructure was examined on polished and Picral etched D2 Tool steel metallographic samples using Optical Microscope.

\section{RESULTS AND DISCUSSION}

\subsection{Microstructure}

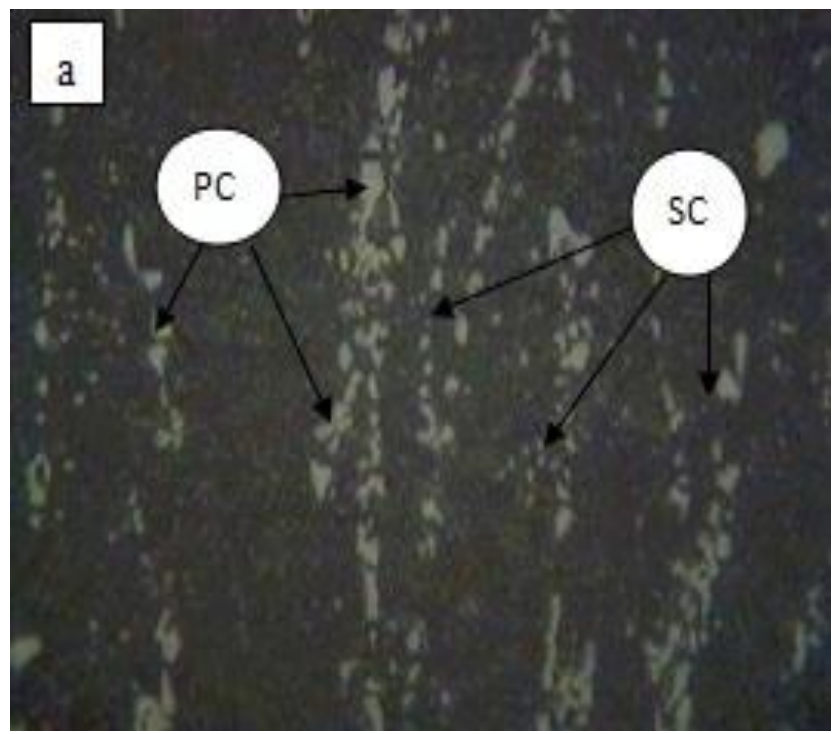

Fig -2: Optical Micrograph of CHT sample [500X]

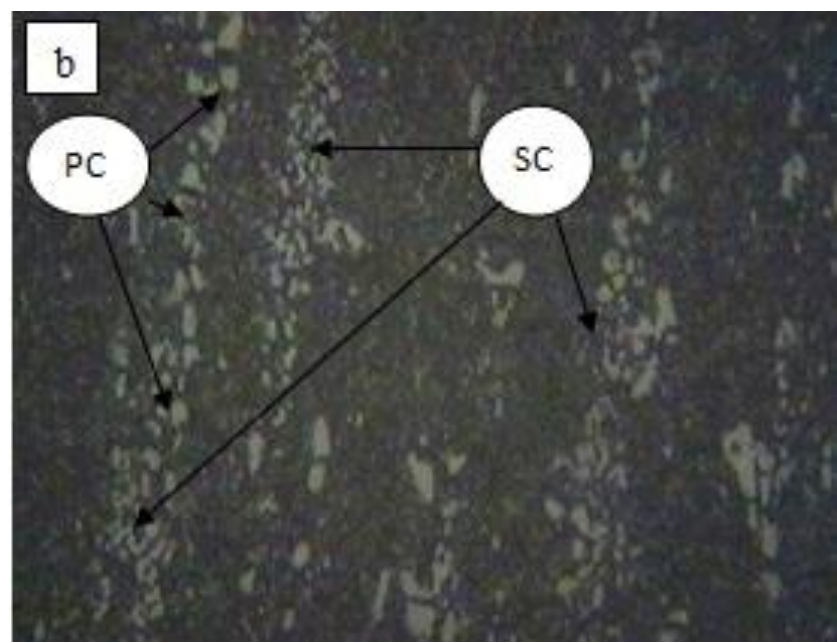

Fig -3: Optical Micrograph of DCT sample [500X]

The optical microstrcture of CHT and DCT Sample is as shown in fig.2. The microstructure shows large irregularly shaped primary carbides (PCs) and small sperical secondary carbides (SCs). The micrograph shows that the carbide precipitation is more in DCT samples than CHT sample. DCT samples have more precipitation and uniform distribution of fine secondary carbide particles than CHT samples.

\subsection{Surface Roughness}

The Surface Roughness values ( $\mathrm{Ra}$ and $\mathrm{Rt}$ ) of the CHT and DCT D2 Tool Steel metallographic samples are as shown in table 2. The DCT samples have less roughness values than CHT samples. The Deep Cryogenic treatment on D2 Tool Steel has shown significant improvement in the surface finish. The DCT has resulted in $15.51 \%$ improvement in surface finish of DCT sample as compared to CHT samples.

Table -2: Surface roughness of CHT and DCT sample

\begin{tabular}{|l|l|l|l|}
\hline Sr. No. & Sample Code & Ra in $\boldsymbol{\mu m}$ & Rt in $\boldsymbol{\mu m}$ \\
\hline 1. & CHT & 0.236 & 2.06 \\
\hline 2. & DCT & 0.2043 & 1.778 \\
\hline
\end{tabular}

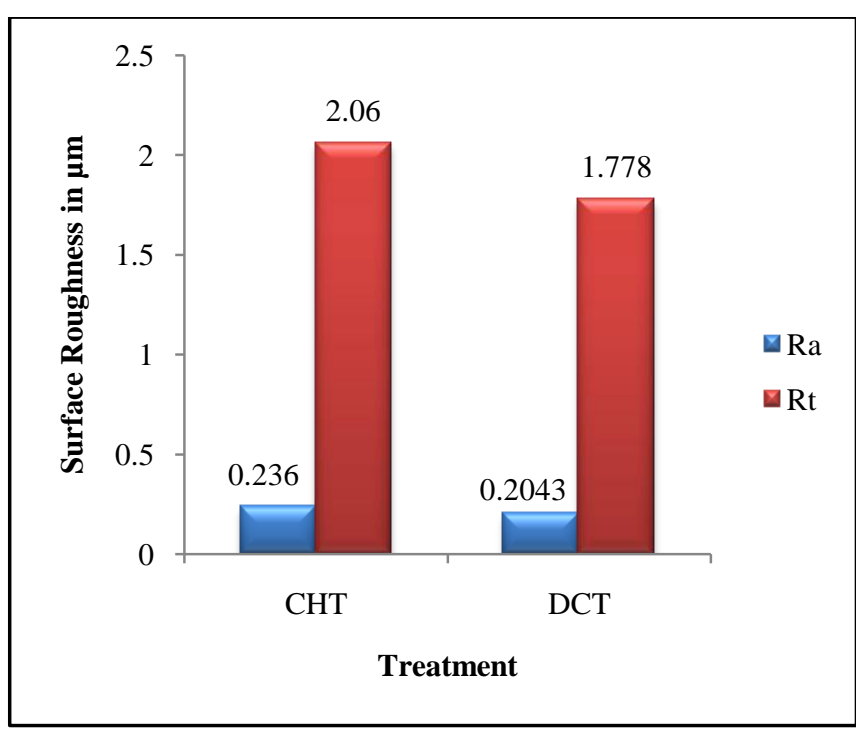

Fig -4: Surface Roughness of CHT and DCT D2 Tool Steel samples

The improvement in Surface finish can be attributed to the release of tensile residual stresses. The compressive residual stresses induced due to the DCT results in reduction of micro cracks thereby improving the surface finish. The increased precipitation and uniform distribution of fine secondary carbides results in filling of micro porosities thus responsible for the improved surface roughness of DCT samples.

\subsection{Hardness}

Table 3 shows the average hardness measurement of D2 Tool Steel metallographic samples after CHT and DCT. Deep Cryogenic Treatment is having minor effect on the hardness of D2 Tool Steel. DCT samples have slightly higher hardness value than CHT sample. The DCT samples shows $1.26 \%$ improvement in hardness than CHT samples. This can be allocated to the transformation of small amount of retained austenite to martensite. 
Table -3: Hardness of CHT and DCT samples

\begin{tabular}{|l|l|l|}
\hline Sr. No. & Sample code & Hardness (HRC) \\
\hline 1. & CHT & 52.53 \\
\hline 2. & DCT & 53.2 \\
\hline
\end{tabular}

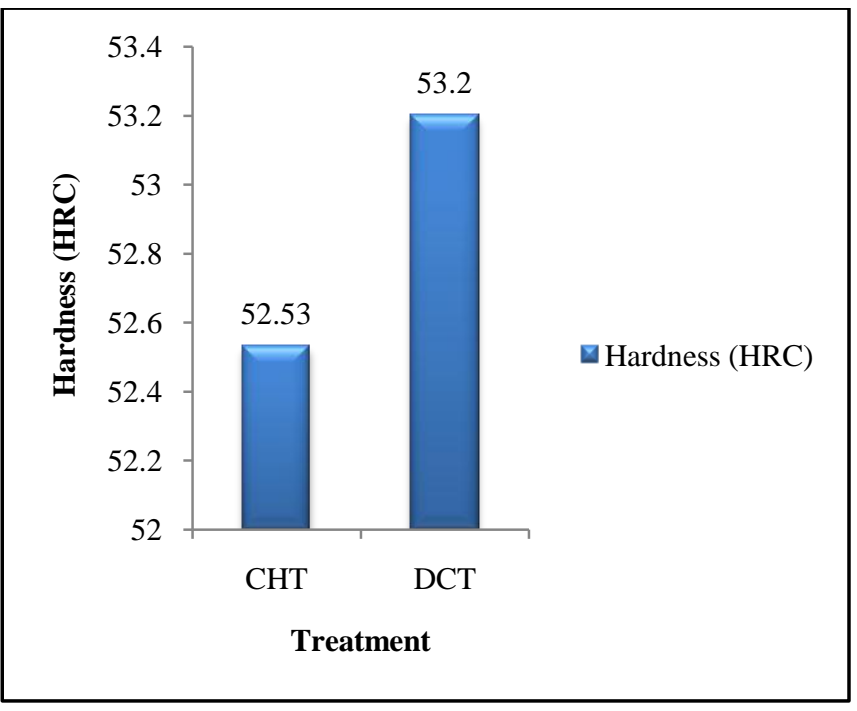

Fig -5: Hardness of CHT and DCT D2 Tool Steel samples

\subsection{Dimensional Stability / Distortion Analysis}

Table-4: Percentage distortion of Navy C-ring after CHT and DCT

\begin{tabular}{|l|l|l|l|}
\hline Sr. No. & \multirow{2}{*}{ CMM Parameters } & \multicolumn{2}{|l|}{$\%$ Distortion } \\
\cline { 3 - 4 } & & CHT & DCT \\
\hline 1. & Flatness & 59.09 & 84.48 \\
\hline 2. & Outside Diameter & 0.05 & 0.0254 \\
\hline 3. & Cylindricity & -14.67 & 4.52 \\
\hline 4. & Inside Diameter & 0.453 & 0.512 \\
\hline 5. & Roundness & -19.25 & -54.31 \\
\hline 6. & Thickness & 0.083 & 0.0792 \\
\hline 7. & Gap width & -0.316 & -0.294 \\
\hline
\end{tabular}

The percentage distortion in Navy C-rings after conventional heat treatment (CHT) and deep cryogenic treatment (DCT) is depicted in table 4. The conventional heat treatment and deep cryogenic treatment have major effect on the distortion of D2 Tool Steel. There is little difference in the size distortion after CHT and DCT. However the Shape distortion is more pronounced after CHT and DCT. DCT have higher shape distortion in flatness and roundness than CHT. The DCT have resulted in less distortion in cylindricity. After CHT there is 59.09\%, $14.67 \%, 19.25 \%$ distortion in flatness, cylindricity and roundness respectively. The $\%$ distortion with positive value indicates expansion and with negative value indicates contraction.

After DCT the distortion in flatness and roundness is increased where as it is decreased in cylindricity. After DCT the distortion in flatness, cylindricity and roundness is $84.48 \%, 4.52 \%,-54.31 \%$ respectively. The higher shape distortion in DCT is attributed to the section sensitivity of
D2 Tool steel. Thin sections cool more rapidly than thick sections. During quenching the large thermal stresses are set in the C-ring due to the thermal gradient between thin gap width sections and thick core section. The thermal stresses induced during quenching in DCT are not completely relieved by low temperature tempering. This causes higher distortion in DCT than CHT.

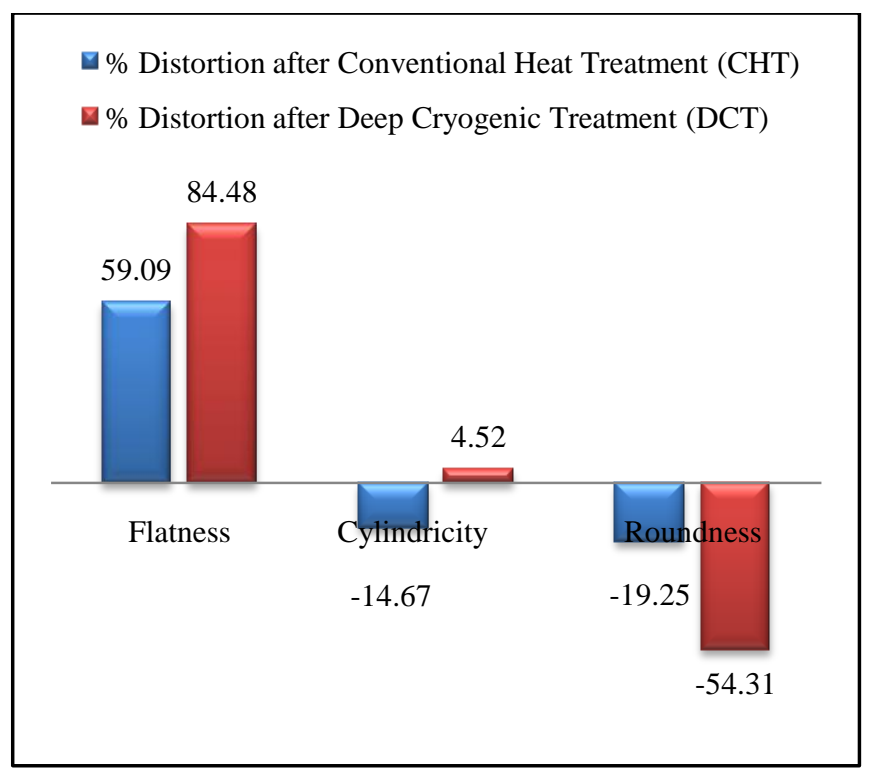

Fig -6: Percentage shape distortion after CHT and DCT

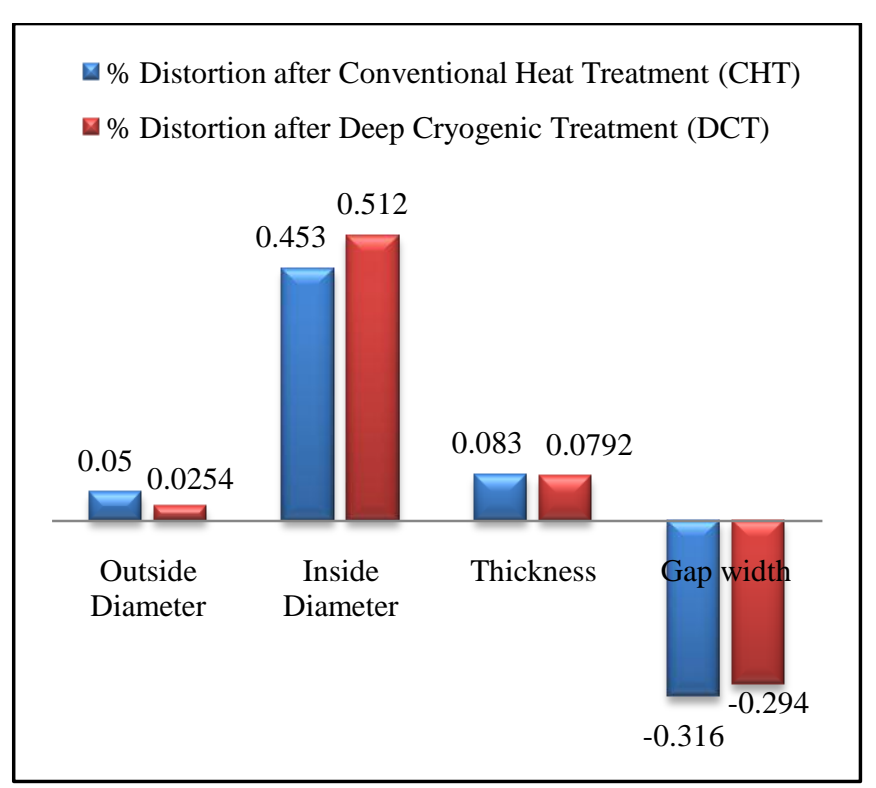

Fig -7: Percentage Size distortion after CHT and DCT

\section{CONCLUSION}

- DCT samples have improved surface roughness than CHT sample. There is $15.51 \%$ improvement in surface finish of deep cryogenically treated D2 Tool steel sample. The improved surface finish is attributed to the release of tensile residual stresses thereby reducing the tendency of micro cracking. The more precipitation and uniform distribution of fine secondary carbides 
causes filling of micro porosities. This leads to improved surface finish of DCT sample.

- The hardness of D2 Tool steel sample is slightly increased by DCT. There is $1.28 \%$ improvement in average hardness values due to deep cryogenic treatment.

- $\quad$ There is little difference in the size distortion caused by CHT and DCT. However DCT have higher shape distortion than CHT. The size distortions are due to the less transformational stresses. The shape distortions are due to the large thermal stresses developed during quenching. The distortion in DCT can be attributed to the section sensitivity of D2 Tool steel.

\section{REFERENCES}

[1]. Natasha A,R., Ghani J.A., Haron C.H.C., Syarif J., The effect of Cryogenic Application on Surface Integrity in manufacturing Process: A Review, Journal of Applied Sciences and Research, Vol.8 Issue.9, pp: 4880-4890,2012.

[2]. Diekman, F., Cold and Cryogenic Treatment of Steel, ASM Handbook, 2013, Volume 4A, Steel Heat Treating Fundamentals and Processes.

[3]. Totten George E., Bates C.E., Clinton N.A., Handbook of Quenchants and Quenching Technology, ASM International, The materials information society, 1993.

[4]. Clark A., Comparison of Austempering and Quench-and -tempering processes for Carburized Automotive Steel, M.Sc Thesis, University of Windsor, 2013.

[5]. Amini, K., Nategh, S., Shafyei, A., Rezaeian, A., The effect of deep cryogenic treatment on mechanical properties of $80 \mathrm{CrMo} 125$ tool steel, International Journal of ISSI, Vol.7 (2010), No.2, pp.12-17.

[6]. Bensely A., Paulin P., Nagarajan, G., Mohan Lal D., Influence of cryogenic treatment on the dimensional stability of Gear Steel-En 353.

[7]. Leskovesk V. and Ule B., Influence of Deep Cryogenic Treatment on Microstructure, Mechanical Properties and Dimensional changes of Vacuum Heat treated High Speed Steel, Heat Treatment of Metals, Vol.3, pp. 72-76, 2002.

[8]. Lomte S. V., Investigation of the influence of Deep Cryogenic Treatment on the residual stresses of HCHC D2 Steel using X-Ray Diffraction, Material Science and Manufacturing Technology, 2007 , pp: 447-460.

[9]. Diekman, Cryogenic Processing: Myths, Methods and Processes, Mould making Technologies (1999) pp: 27-31.

[10]. Da Silva, Flávio J., Franco, Sinésio D.,Machado, Álisson R., Ezugwu, Emmanuel O., Souza, Antônio M., Performance of cryogenically treated HSS tools, Wear 261 (2006) 674-685. 